\title{
Immunophenotyping in incidental gastrointestinal neuroendocrine tumors: study at tertiary care centre
}

\author{
Rachana R Lakhe, Ravi M Swami, Preeti Doshi, Purva Kulkarni, Narayan \\ Subramanian Mani \\ ${ }^{1}$ Department of Pathology,Bharati vidyapeeth (DU) Medical College and Hospital,Pune,Maharashtra, India.
}

\section{Keywords: \\ Chromogranin; Incidental; Ki67 index; Neuroendocrine; Synaptophysin;}

\begin{abstract}
Background: Gastrointestinal neuroendocrine tumors are rare slow-growing tumors with distinct histological, biological, and clinical characteristics that have increased in incidence and prevalence in the last few decades. This study is aimed to find out the incidence of neuroendocrine tumors among the gastrointestinal tumors and to grade gastrointestinal neuroendocrine tumors.
\end{abstract}

Materials and Methods: A total of 119 cases of gastrointestinal tumors of gastrointestinal neuroendocrine was included in the study. The paraffin blocks were retrieved and slides were stained with routine Hematoxylin and eosin, synaptophysin, chromogranin, and Ki67. The histologic grading was done based on mitosis and Ki-67 index as per WHO 2017 NET Classification.

Results: Out of 119 cases of Gastrointestinal Tract tumor, 13 (10.92\%) constituted neuroendocrine tumors. Duodenum was the most common site (38\%) followed by the appendix $(23 \%)$. The majority $(1.9 \%)$ of the cases were categorized as of grade 1 followed by $2.3 \%$ of grade 2 and $1.19 \%$ of grade 3 . Immunohistochemically, chromogranin, and synaptophysin were strongly expressed in all ten cases of neuroendocrine tumors. The Ki67 labeling index was $<3 \%$ in 10 cases, while it was in the range of $3-20$ $\%$ in 2 cases and $>20 \%$ in one case.

Conclusions: The incidence of gastrointestinal neuroendocrine tumors is on the rise. They should be considered in developing a differential diagnosis. Hence use of diagnostic modalities such as immunohistochemistry should be implemented for better treatment.

\section{Correspondence:}

Dr. Ravi M Swami, MD

Department of Pathology, Associate Professor,

Bharati Vidyapeeth Deemed to be University and Medical College,

Pune, India.

ORCID ID: 0000-0002-9363-5798

Email:drravimswami@gmail.com

Received : June $30^{\text {th }} 2020$; Accepted : September $29^{\text {th }} 2020$

Citation: Lakhe RR, Swami RM, Doshi P, Kulkarni P, Mani NS.

Immunophenotyping in incidental gastrointestinal neuroendocrine tumors: study at tertiary care centre. J Pathol Nep 2020;10:1751-5. DOI 10.3126/jpn.v10i2.29754

Copyright: This is an open-access article distributed under the terms of the Creative Commons Attribution 4.0 International License, which permits unrestricted use, distribution, and reproduction in any medium, provided the original author and source are credited.

\section{INTRODUCTION}

Neuroendocrine tumors (NETs) are heterogeneous, slowgrowing tumors that arise from neuroendocrine cells present throughout the body. ${ }^{1}$ The age-standardized rate of colorectal cancers and stomach cancer in 2018 in India were 4.4 and 4.5 per $100,000 .^{2}$ They are categorized into the foregut (bronchial, gastric, duodenal, and pancreas), midgut (jejunal, ileal, appendiceal, and ascending/transverse colon), and hindgut (distal colon and rectum) tumors. ${ }^{3}$ One of the most common locations of neuroendocrine tumors in the small intestine with the primary tumor, often located in the distal ileum. The annual incidence of small intestinal NET 
is approximately $0.8 / 100.000$. Among the gastrointestinal NET, the small intestine NET is most common. ${ }^{4,5}$ Based on the Surveillance Epidemiology and End Results (SEER) Program registries, the incidence of neuroendocrine tumors of gastrointestinal tumors in Asians is 3.19 per 100,000. ${ }^{6}$

The clinicopathological profile of NETs in the Indian population differs from Western countries. There are few Indian studies regarding epidemiology, presentations, and histopathological characteristics in patients with NETs.

In this study, we have studied the trends of gastrointestinal neuroendocrine tumors among all gastrointestinal (GI) tumors received over 3 years along with IHC and compared the findings with existing Indian studies.

\section{MATERIALS AND METHODS}

This was a cross-sectional study conducted in from 2018 to 2020. Permission was obtained from the Institutional Review Committee. Among the total 119 gastrointestinal tumor cases, 13 cases were of neuroendocrine tumor. Blocks of these 13 cases were retrieved and stained with hematoxylin and eosin(HE). Immunohistochemistry was performed for chromogranin, synaptophysin, Ki67 for these cases. A positive control was performed along with all the cases. All the slides were examined under a microscope, and each case was studied concerning age, clinical presentation, endoscopic findings, and microscopic picture, based on which a final diagnosis was given. In this study, we have classified the tumors using WHO 2017 NET Classification.

For precise evaluation of the grading, criteria of a minimum of $50 \mathrm{HPFs}$ for the mitotic count and at least 500 cells for the Ki-67 labelling index was followed as per WHO $2017 .{ }^{8}$ The data were entered in Microsoft EXCEL and mean, percentage were analysed.

\section{RESULTS}

The total number of GI tumors identified between 2018 and 2020 was 119 out of which 13 cases were neuroendocrine tumors that are comprised of $10.92 \%$. Age-wise distribution of neuroendocrine case is given in figure 1 . Out of 13 cases, $10(1.3 \%)$ were males and $3(0.3 \%)$ were females. The most common clinical complaint was abdominal pain 98/13; $61.5 \%$ ) followed by dyspepsia (Table 1). Endoscopically most of them presented as a polypoidal lesion (Table 1). Two patients $(15.38 \%)$ presented with acute appendicitis and two patients (15.38\%) presented with features of bowel obstruction. One patient presented with jaundice and had a periampullary mass in the endoscopy.

The majority of the tumors were located at the duodenum $(\mathrm{n}=5 ; 38 \%)$ followed by the appendix $(\mathrm{n}=3 ; 23.07 \%)$ and ileocecal region $(15.38 \%)$. There was 1 case each in which

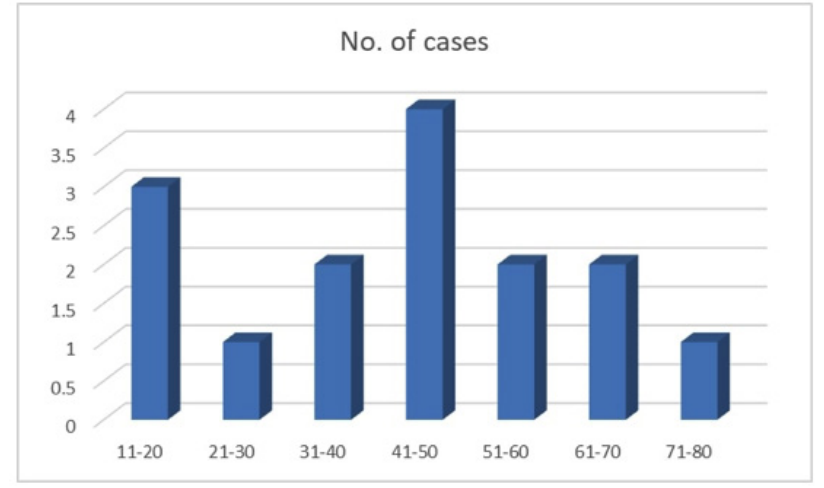

Figure 1: Age-wise distribution of neuroendocrine tumor

the tumor was located in the stomach, periampullary region, and colon.

Microscopically GI-NET showed classic morphology, well-circumscribed mass composed of uniform tumor cells having round nuclei with "salt and pepper" (stippled) chromatin (fig. 2A and B). Tumor nests are arranged in trabecular, glandular, acinar, and solid patterns. Immunohistochemically, chromogranin, and synaptophysin were strongly expressed in all neuroendocrine tumors (fig. $3 \mathrm{~A}$ and B). Ki67 (fig. 3c) labelling index was $<3 \%$ (grade 1 ) in ten cases while it was in the range of $3-20 \%$ (grade 2 ) in two cases and $>20 \%$ (grade 3 ) in one case (WHO 2017 NET Classification). (Table 2)

Table 1: Clinical details of the study population $(n=13)$

\begin{tabular}{lc}
\hline Clinical details & $\mathbf{N}(\%)$ \\
Abdominal pain & $8(61.5)$ \\
Dyspepsia & $2(15.38)$ \\
Obstruction & $2(15.38)$ \\
Jaundice & $1(7.69)$ \\
\hline Duodenal polyp & $5(38.46)$ \\
\hline Gastric body polyp & $1(7.69)$ \\
\hline Periampullary mass & $1(7.69)$ \\
\hline Bowel thickening & $2(15.38)$ \\
\hline Appendicitis & $2(15.38)$ \\
\hline Ileocaecal mass & $1(7.69)$ \\
\hline None & $1(7.69)$ \\
\hline
\end{tabular}

Table 2: Correlation of Ki67 labeling index in neuroendocrine tumor (WHO 2017classification) $(n=13)$

\begin{tabular}{lccc}
\hline Grade & \multicolumn{3}{c}{ ki 67 index (No. of cases) } \\
$\begin{array}{l}\text { Abdominal } \\
\text { pain }\end{array}$ & $<3 \%$ & $3-20 \%$ & $>20 \%$ \\
Grade 1 & 10 & 00 & 00 \\
\hline Grade 2 & 00 & 02 & 00 \\
\hline Grade & 00 & 00 & 01 \\
\hline
\end{tabular}




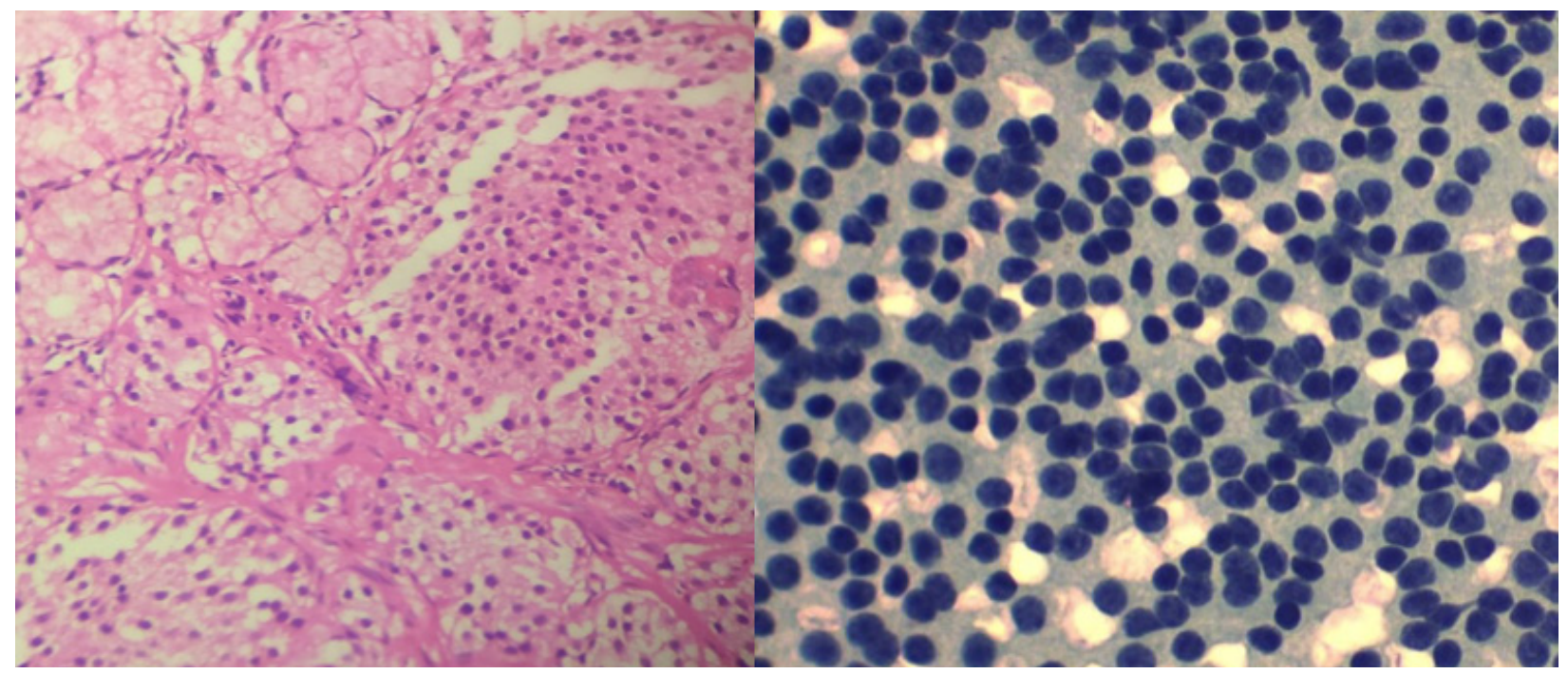

Figure 2: A) Photomicrograph showing neurendocrine tumor with Brunner's gland of duodenum (HE stain; X400). B) Neuroendocrine tumor showing uniform small round cells (400X)

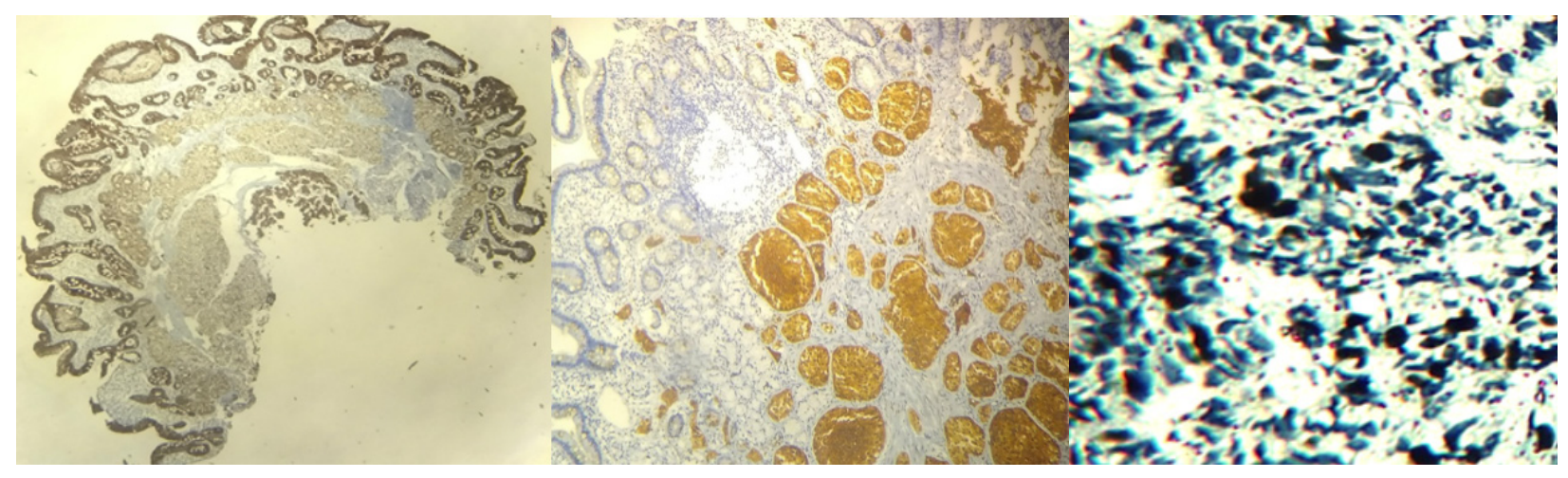

Figure 3: Immunohistochemistry of the neuroendocrine tumor showing: a) strong positivity for chromogranin (100x); b) Strong positivity for synaptophysin (400x); and c) High Ki67 in a neuroendocrine tumor (400x)

Out of 13 cases, 11 were followed up. Out of these one case with adenocarcinoma of stomach died of disease, rest had disease-free survival of one year and no further progression or transformation of tumor into malignancy.

\section{DISCUSSION}

Neuroendocrine tumors (NETs) of the small intestine (siNETs) were first described by Otto Lubarsch in 1888 . In 1907, the German pathologist Siegfried Oberndorfer referred to these tumors as characterized by the same morphology as 'carcinoids'.?

Neuroendocrine tumors (NET) are malignant tumors that arise from neuroendocrine cells and are increasingly reported in recent times due to the widespread use of endoscopy. Most of the patients present with nonspecific symptoms such as abdominal pain, bloating, and weight loss. A few patients may present with features of classical carcinoid syndrome characterized by flushing and diarrhea. ${ }^{8,9} \mathrm{We}$ had no case of such a classical presentation. All were sporadic cases of NET and syndromic association was not identified.
This study had male preponderance, which correlated with the study by Kulkarni RS and Uppin MS. ${ }^{10,11}$

In the present study, the common location was the duodenum followed by an appendix which correlated with the study by Uppin MS. ${ }^{11}$ The most common primary site of colonic NENs is the cecum, followed by a sigmoid colon and ascending colon as per Western literature. Rectal NENs occur at a high frequency among the Asian population than among white patients. ${ }^{12}$ In another study by Amrapurkar $\mathrm{DN}$, an Indian retrospective analysis of GEP-NETs, the most common site of the primary tumor was the stomach $(30.2 \%)$, followed by the pancreas $(23.3 \%) .{ }^{13}$ But in the present study, the duodenum was the most common site of occurrence.

NETs are assessed based on Grade, differentiation, and stage. Grading is based on mainly Ki67 and mitotic index. Ki67 labeling index was done by calculating 500 cells in areas of hotspots in 50 high power fields. An increased mitotic activity and proliferation index have been associated with aggressive clinical behavior and poor prognosis. ${ }^{14}$ 
According to a study by Kapoor R, the age of presentation of GI NET in the Indian population is found to be in later decades which correlates with the present study. ${ }^{15}$

In 2010, the World Health Organization classified NETs into mixed adeno-neuroendocrine carcinoma, neuroendocrine carcinoma, and mixed adeno-neuroendocrine carcinoma (MANEC), tumors that have both exocrine and endocrine components of at least $30 \%$ each. There are only 12 instances or cases of MANEC reported from India. ${ }^{16-19}$ In 2017, the classification of GI NET is slightly modified to change in terminology mixed adeno-neuroendocrine carcinoma (MANEC) by the mixed neuroendocrine nonneuroendocrine tumor (MiNEN). In addition, percentage of mitosis from $<2$ to $<3 \%$. Also, the G3 Category is further subclassified into small cell type and large cell type., ${ }^{8,14}$

Mixed adeno-neuroendocrine carcinomas contain both malignant glandular and NEC components, and each component should be more than one-third of the tumor volume. ${ }^{20}$ Our study had one case of Mixed neuroendocrine non-neuroendocrine tumor (MiNEN).

There is limited data available on epidemiology and patterns of neuroendocrine tumors in India. Even among the neuroendocrine tumors, the incidence of only gastrointestinal tumors is less common. This study highlights the low incidence of neuroendocrine gastrointestinal tumors among all gastrointestinal tumors studied.

In 2017, there were substantial changes in the grading and staging systems for NEN. First, the World Health Organization (WHO) grading system changed the definition of grade 3 NET/NEC. Second, the $8^{\text {th }}$ American Joint Committee on Cancer (AJCC) changed its TNM staging system for NEN. Treatment strategies changed according to the new concepts of grade 3 NET/NEC. ${ }^{21}$

In the revised grading system, a new subset of welldifferentiated NENs has been recognized, i.e., lesions that are morphologically well-differentiated and often identical to grade 1 or grade 2 NET but have a high Ki-67 index ( $>$ $20 \%)$.

\section{CONCLUSIONS}

The incidence and prevalence of neuroendocrine tumors are increasing. There is limited Indian data on behavior and prevalence of NETs in the Gastrointestinal tract. Overall, the above studies showed that there are possible ethnic and regional, behavioral variations in the primary site of origin of NETs as compared to Western literature. The duodenum was the most common site of occurrence. CT, MRI, and for small NETs endoscopy has been widely used to accurately locate the site of NETs. Awareness may reduce delay in diagnosis and facilitate expert multidisciplinary care.

\section{Conflict of Interest: None}

\section{REFERENCES}

1. Patanè E, Sgardello SD, Guendil B, Fournier I, Abbassi Z. Unexpected Finding of a Small Intestinal Neuroendocrine Tumor: A Case Report and Literature Review. Am J Case Rep. 2020;21: e917759. Crossref

2. Patil PS, Saklani A, Gambhire P, Mehta S, Engineer R, De'Souza A, Chopra S, Bal M. Colorectal Cancer in India: An Audit from a Tertiary Center in a Low Prevalence Area. Indian J Surg Oncol. 2017;8(4):484490. $\underline{\text { Crossref }}$

3. Howe JR, Cardona K, Fraker DL, Kebebew E, Untch BR, Wang YZ, et al. The Surgical Management of Small Bowel Neuroendocrine Tumors: Consensus Guidelines of the North American Neuroendocrine Tumor Society. Pancreas. 2017 ;46(6):715-731. $\underline{\text { Crossref }}$

4. Kim JY, Hong SM. Recent updates on neuroendocrine tumors from the gastrointestinal and pancreatobiliary tracts. Arch Pathol Lab Med. 2016;140(5):437-48. Crossref

5. Hoej LB, Nykjær KM, Gronbaek H. Incidence and survival of patients with small intestinal neuroendocrine tumours in a Danish NET center. Sci. World J. 2012;2012:206350. Crossref

6. Huang PY, Tsai KL, Liang CM, Tai WC, Rau KM, $\mathrm{Wu} \mathrm{KL}$, et al. Prognostic factors of patients with gastroenteropancreatic neuroendocrine neoplasms. Kaohsiung J Med Sci. 2018;34(11):650-6. Crossref

7. Selberherr A, Niederle MB, Niederle B. Surgical treatment of small intestinal neuroendocrine tumors G1/G2. Visceral Medicine. 2017;33(5):340-3. Crossref

8. Bosman FT, Carneiro F, Hruban RH, Theise ND, eds. WHO Classification of Tumours of the Digestive System. 4th ed. Lyon, France: IARC Press; 2010. Pp280

9. Mills SE, Greenson JK, Hornick JL, Longacre TA, Reuter VE. Intestinal neoplasms. In Sternberg's diagnostic surgical pathology. Lippincott Williams \& Wilkins; 2015.1577-82p.

10. Kulkarni RS, Anand AS, Parikh SK, Panchal 
HP, Patel AA, Mehta DP, Patel P. Clinical and epidemiological profile of neuroendocrine tumors: An experience from a regional cancer center from Western India. South Asian J. Cancer. 2019;8(3):198. $\underline{\text { Website }}$

11. Uppin MS, Uppin SG, Sunil CS, Hui M, Paul TR, Bheerappa N. Clinicopathologic study of neuroendocrine tumors of gastroenteropancreatic tract: a single institutional experience. J. Gastrointest. Oncol. 2017;8(1):139-47. Crossref

12. Jiang $\mathrm{M}$, Tan $\mathrm{Y}, \mathrm{Li} \mathrm{X}, \mathrm{Fu} \mathrm{J}, \mathrm{Hu} \mathrm{H}, \mathrm{Ye} \mathrm{X}$, et al. Clinicopathological Features and Prognostic Factors of Colorectal Neuroendocrine Neoplasms. Gastroenterol Res Pract. 2017;2017:4206172. $\underline{\text { Crossref }}$

13. AmarapurkarDN,JunejaMP,PatelND,AmarapurkarAD, Amarapurkar PD .A retrospective clinico-pathological analysis of neuroendocrine tumors of the gastrointestinal tract. Trop Gastroenterol. 2010; 31(2):101-4. Website

14. Nagtegaal ID, Odze RD, Klimstra D, Paradis V, Rugge M, Schirmacher P, et al. WHO Classification of Tumours Editorial Board. The 2019 WHO classification of tumours of the digestive system.Histopathology. 2020;76(2):182-8. $\underline{\text { Crossref }}$

15. Kapoor R, Bhattacharyya T, Gupta R, Mitta BR, Kalra N. A systematic review of management of neuroendocrine tumors: An experience from a tertiary care centre from India. Clin Cancer Investig J. 2014;3:363-72. $\underline{\text { Website }}$
16. Chawla N, Reddy SJ, Agrawal M. Amphicrine tumour of gastric antrum - A case report. Rev Esp Patol 2013;46:79-82. Website

17. Yacob M, Sudhakar CB, Samarasam I. Composite glandular and neuroendocrine carcinoma of the stomach-two case reports. J Gastric Dis Ther 2015;56:24. Website

18. Azad S, Shukla D, Garg A, Negi SS, Malhotra V. Mixed adenoneuroendocrine carcinoma of the gallbladder, histopathological features. Indian J PatholMicrobiol 2015;58:543-5. $\underline{\text { Website }}$

19. Kamboj M, Gandhi JS, Gupta G, Sharma A, Pasricha S, Mehta A, et al. Neuroendocrine carcinoma of gall bladder: A series of 19 cases with review of literature. J Gastrointest Cancer 2015;46:356-64. Crossref

20. Vijayakumar S, Jacob SE, Badhe BA, Srinivas BH. Mixed adenoneuroendocrine carcinoma: A report of four cases from South India.Journal of Health Research and Reviews. 2019;6(1):31. $\underline{\text { Crossref }}$ 